\title{
Erratum to: Big Pharma in Residency Training: Losing More Than a Free Lunch?
}

\author{
Stephanie Peglow • David Spiegel • Hasan Memon • \\ Gregory Briscoe
}

Published online: 9 October 2014

(C) Academic Psychiatry 2014

Erratum to: Acad Psychiatry (2014) 38:516-517

DOI 10.1007/s40596-014-0146-3

Hasan Memon's name appeared incorrectly in the original publication of this article. It appears correctly here.

The online version of the original article can be found at http://dx.doi.org/ 10.1007/s40596-014-0146-3.

S. Peglow $(\varangle) \cdot$ D. Spiegel $\cdot$ H. Memon $\cdot$ G. Briscoe Eastern Virginia Medical School, Norfolk, VA, USA

e-mail: peglows1@evms.edu 